\title{
Laparoscopic Sclerotherapy of Child's Pancreatic Cyst
}

DOI: 10.17691/stm2015.7.2.25

Received June 4, 2014

L.A. Otdel'nov, Assistant, Department of Surgery, Postgraduate Faculty';

V.P. Obryadov, PhD, Head of the Department Infantile Surgery²;

E.A. Rozhdyonkin, Junior Researcher ${ }^{3}$;

G.M. Lukoyanova, MD, DSc, Professor, Department of Surgery, Postgraduate Faculty ${ }^{1}$

${ }^{1}$ Nizhny Novgorod State Medical Academy, 10/1 Minin and Pozharsky Square, Nizhny Novgorod, 603005,

Russian Federation;

${ }^{2}$ Nizhny Novgorod Regional Children Hospital, 211 Vaneeva St., Nizhny Novgorod, 603136, Russian Federation;

${ }^{3}$ Privolzhsky Federal Research Medical Center, Ministry of Health of the Russian Federation,

18 Verkhne-Volzhskaya naberezhnaya St., Nizhny Novgorod, 603155, Russian Federation

The paper presents clinical supervision of child's post-traumatic pancreatic cyst. The described case demonstrates efficiency of comprehensive approach to evoked cyst treatment which comprises acute pancreatitis therapy with dynamic assessment of the results and subsequent surgical measure. The authors demonstrated capabilities of ultrasound investigation in this pathology diagnostics and conservative treatment complexity. The supervision is of interest because of unconventional approach to the operation: the patient received cyst laparoscopic drainage and sclerotherapy. The described minimal invasion resulted in absolute recovery.

Key words: pancreatic cyst; laparoscopy; cyst sclerotherapy; outer cyst drainage.

In recent decades there is a distinct tendency towards pancreatitis occurrence growth both with adults and children. Acute and chronic pancreatitis accrues up to $25 \%$ of the child's digestive system diseases [1]. Evoked pancreatic cysts developed on trauma and inflammatory process background are relatively rear childhood pathology but still requiring personalized comprehensive approach [2-6].

Our observation is set forth below. The child's parents provided the informed consent for the investigation.

Patient B., an 8 years old child, was admitted to the surgery of the Nizhny Novgorod Regional Children Hospital on 27.09.2012, in a month after getting injured, i.e. on 28.08.2012 when the patient fell off the bicycle. The patient was surgically operated in the Central District Hospital in an expedited manner: in the course of operation they revealed pancreas contusion, lesser omentum hematoma, retroperitoneal space hematoma, mesocolon rupture. Laparotomy, mesocolon rupture mesorrhaphy were made.

Post-surgical period they noticed pyretic fever, abdominal pains, nausea and vomiting; according to ultrasonography data - pancreas tail cyst symptoms. In blood - rise of amylase up to 100 norms. The provided conservative treatment gave no positive results, for this reason the child was transferred to the surgery of the regional hospital. At admission, according to ultrasonography data as of 27.09.2012: large pancreas mass (head - $22 \mathrm{~mm}$, body $12 \mathrm{~mm}$, tail $-36 \mathrm{~mm}$ ); the pancreas has even, clear boundaries, diffusely inhomogeneous echo structure (due to minor high-echogenic inclusions), echogenicity is moderate high, the duct is not dilated, in tail projection they located a single space-occupying lesion $38 \times 48 \times 33 \mathrm{~mm}$, volume $29 \mathrm{~cm}^{3}$, with clear boundaries, thin capsula having an ovalary form. Anechogenic content in extraorganic space of small pelvis - in the amount of $130 \mathrm{ml}$ (ascites symptoms), splenomegaly symptoms. Comprehensive conservative treatment was started, inclusive of clinical nutrition, infusion therapy, antibacterial therapy, administration of octreotide, Creon, Cerucal, Bifidumbacterinum, and Almagel (aluminium hydroxide/magnesium hydroxide). Improvement was observed: pain management, inflammatory process subsiding, decrease of blood amylase level to 2 norms. According to follow-up ultrasonography data - no negative dynamics: a space-occupying lesion in pancreas tail of $27 \times 49 \times 41 \mathrm{~mm}$, volume $28 \mathrm{~cm}^{3}$, of ovalary form with even clear boundaries, anechogenic content with echogenic mural inclusions, ascites symptoms (Figure 1). The patient was dismissed from hospital on day 8 in satisfactory condition with recommendations of faithful adherence to diet, taking enzyme preparations.

According to follow-up ultrasonography data in one month and a half a negative dynamics was observed: increase in volume of tail fluid lump up to $130 \mathrm{~cm}^{3}$, pancreas phologistic changes - increase of dimensions, uneven boundaries (Figure 2). In order to resolve the issue of surgical treatment the patient was rehospitalized to the surgery of the regional hospital on 14.12.2012. Taking into account the persisting fluid lump in the area of pancreas tail and other negative

For contacts: Otdel'nov Leonid Alexandrovich, e-mail: leonotdelnov@yandex.ru 


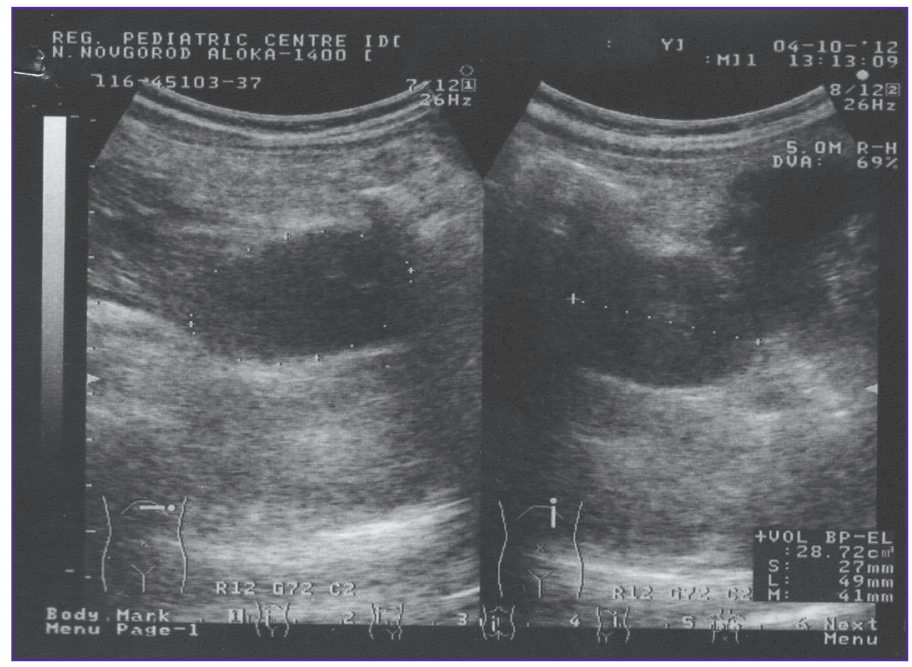

Figure 1. US-scanning image as of 04.10 .2012 , pancreatic tail cyst, volume $28 \mathrm{~cm}^{3}$

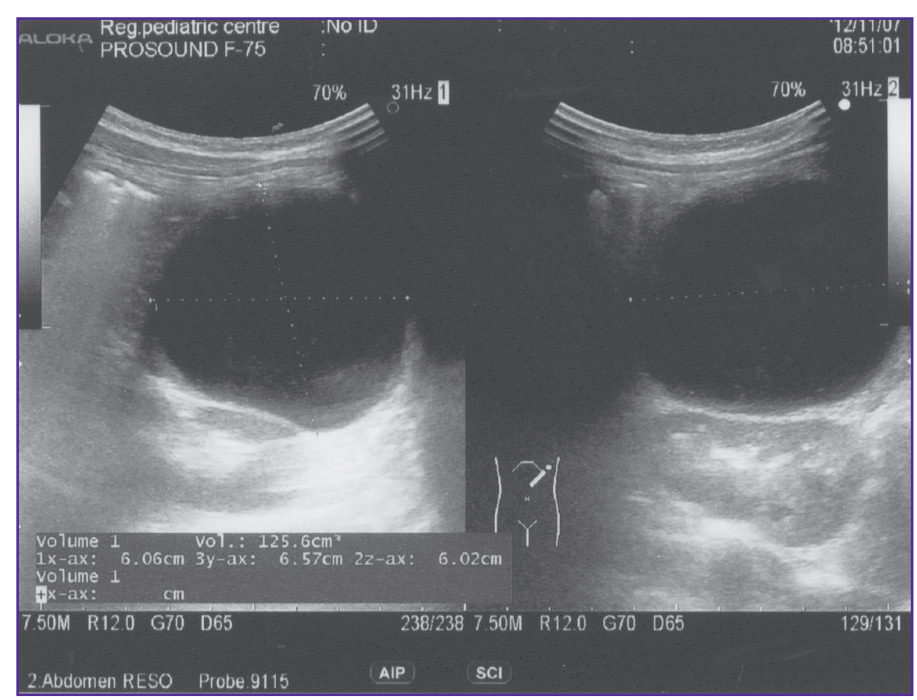

Figure 2. US-scanning image as of 07.11.2012, negative dynamics: cyst volume increase to $130 \mathrm{~cm}^{3}$

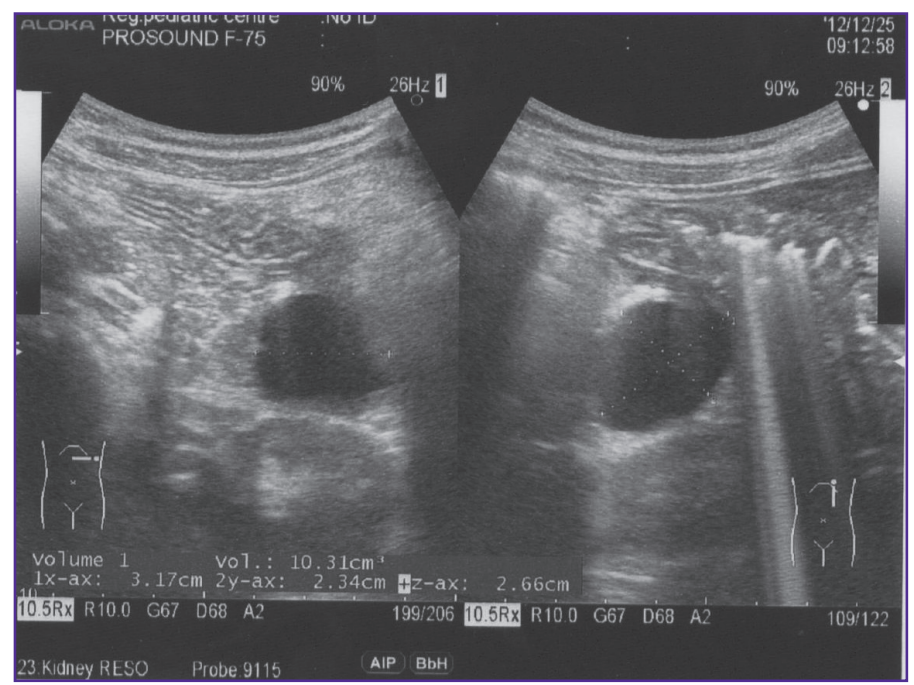

Figure 3. US-scanning image as of 25.12.2012, day 6 after the operation: cyst cavity decrease to $10.3 \mathrm{~cm}^{3}$ dynamics according to ultrasonography data a decision was made to provide the surgical treatment.

The operation was carried out on 19.12.2012: laparoscopic sclerotherapy, pancreatic cyst drainage. After application of pneumoperitoneum, 4 trochars were introduced in the abdominal cavity. Using the bipolar coagulation they incised the gastrocolic ligament, uncovered lesser omentum cavity. In the course of operative exploration, a cyst of up to $5 \mathrm{~cm}$ in diameter was revealed in the pancreas tail area. It was partially mobilized and punctured with the needle; in result $10 \mathrm{ml}$ clear exudate free of flocculus was received. A trochar with a catheter (a set for paracentetic cystostomy) was introduced to the abdominal cavity via a centesis in the left hypochondrium. The cyst was punctured - the catheter was introduced in the cavity through which the cavity was washed with a mixture of $0.1 \%$ adrenalin and $0.25 \%$ novocaine (1:20) with 2 min exposure after which the dilution was removed. Then they introduced $4 \mathrm{ml}$ of cooled $95 \%$ ethyl alcohol into the cyst cavity which was evacuated in $5 \mathrm{~min}$. The abdominal cavity was drained and the trochars removed. The drainage was fixed to the skin. They put stitches in wounds.

Postoperative period proceeded unremarkable. The drainage was removed on day 2 . The wounds healed up by primary intention. In the postoperative period clinical nutrition, infusion therapy, antibacterial therapy, Creon, Ultop were prescribed. According to ultrasonography dynamic data (on day 6 after operation): they located a single space-occupying lesion in pancreas tail of $31.7 \times 23.4 \times 26.6 \mathrm{~mm}$, volume $10.3 \mathrm{~cm}^{3}$, of ovalary form with even clear boundaries, anechogenic content (Figure 3). The patient was dismissed from hospital on day 7 after the operation in satisfactory condition.

According to follow-up ultrasonography data in one month and a half: in the tail projection - a rounded anechogenic formation with even clear boundaries diameter $18-19 \mathrm{~mm}$ and volume $\max 4 \mathrm{~cm}^{3}$. In the course of dynamic examination in 9 months: the pancreas $18.4 \times 5.6 \times 18.7 \mathrm{~mm}$ in size with even clear boundaries of diffusely inhomogeneous structure due to minor high-echogenic inclusions with regular echogenicity, the duct is not dilated, no spaceoccupying lesions found. There is no free fluid in the abdominal cavity (Figure 4). There is no pain syndrome and dyspeptic disorder, carbohydrate metabolism is compensated.

Conclusion. The presented observation of the post-traumatic pancreatitis step-wise treatment demonstrates complexity of such patient group management due to development of complications in form of post-traumatic cyst resistant to the conservative treatment. Patients with acquired pancreas cyst require a comprehensive approach 
Figure 4. US-scanning image as of 24.09.2013, long-term outcome after 9 months after the operation: no spaceoccupying lesions

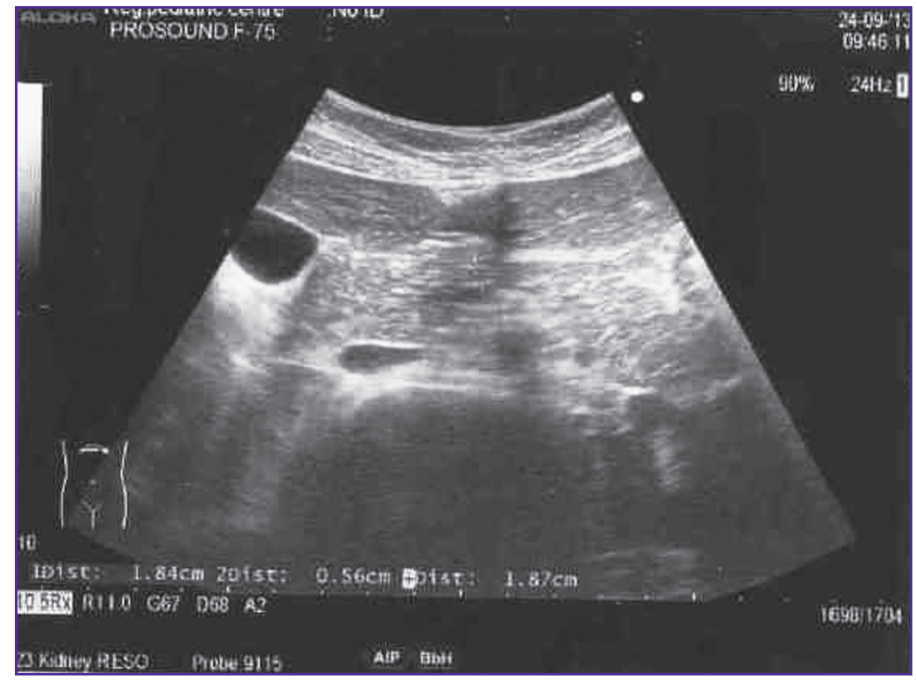

which at the first stage comprises conservative treatment of acute pancreatitis continued at the outpatient treatment stage, active dynamic monitoring with assessment of clinical laboratory indicators and ultrasonography data. Should surgical treatment is required, the selection of surgical support shall be based on minimally invasive intervention options. In the above case the comprehensive approach resulted in the benign outcome.

Study Funding and Conflict of Interests. The research has not been financed from any source. There are no conflicts of interests associated with this research.

\section{References}

1. Maev I.V., Kucheryavyy Yu.A. Bolezni podzheludochnoy zhelezy [Diseases of the pancreas]. Moscow; 2009; $736 \mathrm{p}$.

2. Gumerov A.A., Zaynullin R.R., Filippova N.P. Posttraumatic pancreatic cyst with 6 years old child. Detskaya khirurgiya 2002; 6: 50-51.
3. Davidenko N.V. Kliniko-funktsional'naya kharakteristika, iskhody i prognoz ostrykh pankreatitov razlichnoy etiologii $u$ detey. Avtoref. dis. ... kand. med. nauk [Clinical-functional profile, outcomes and prognosis of children's various ethiology acute pancreatitis. Abstract of Dissertation for the degree of Candidate of Medical Science]. Moscow; 2006.

4. Bhat N.A., Rashid K.A., Wani I., Wani S., Syeed A. Hydatid cyst of the pancreas mimicking choledochal cyst. Ann Saudi Med 2011; 31(5): 536-538, http://dx.doi. org/10.4103/0256-4947.84638.

5. Brien-Richter A., Grabhorn E., Wenke K., Gansehow R. Hemorrhagic necrotizing pancreatitis with a huge pseudocyst in a child with Grohn's disease. Eur J Gastroenterol Hepatol 2010; 22(2): 234-236, http://dx.doi.org/10.1097/ MEG.0b013e32832ca501.

6. Fujishiro J., Kaneko M., Urita Y., Hashino N., Jinbo T., Sakamoto N., Suzuki H., Komuro H. Enteric duplication cyst of the pancreas with duplicated pancreatic duct. J Pediatr Surg 2011; 46(8): 13-16, http://dx.doi.org/10.1016/ j.jpedsurg.2011.04.056. 